a phylogeny constructed using data from extant taxa ${ }^{11-13}$. In a News and Views article last year ${ }^{14}$, I discussed how fossil species along a transformation series could be used to overturn neontologically based cladograms in certain circumstances ${ }^{15}$. But the transformation series is a paraphyletic concept derived from traditional, synthetic ideas which can be expressed in cladistic terms only by a careful choice of characters used to justify existing ideas of relationship ${ }^{13}$. Jefferies, on the other hand, meets paraphyly head on. Much of the discussion ${ }^{1}$ about Barrandeocarpus concerns how this fossil form can be incorporated in a scheme embracing both paraphyly and transformation series.

Jefferies redefines a group of primitive carpoids called cornutes as the 'stem group' of chordates ${ }^{3.16}$, through which runs the 'stem lineage' to more derived chordates in the 'crown group' (Fig. 2). Each evolutionary novelty along the stem lineage $^{16}$ forms the upper or lower bound of a discrete segment of the stem lineage, called a plesion. Stem groups and plesions are paraphyletic in that they cannot be defined by unique sets of derived characters that exclude crown groups. This is because the character that defines the lower bound of a stem group or plesion is also present, at least primitively, in more 'crownward' forms. Jefferies' use of the plesion concept moves it a considerable distance from its original definition (Fig. $2)^{17}$. His addition of concepts such as the stem lineage has turned the (monophyletic) plesion into a (paraphyletic) lineage segment, an idea he has worked out most extensively in the systematic placement of Barrandeocarpus ${ }^{1}$

Jefferies defines a relatively derived

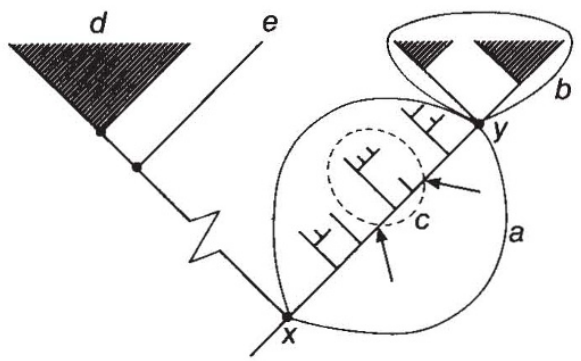

FIG. 2 Some cladistic terminology explained. The right hand side of the diagram shows a stem group $a$, (such as the cornutes), leading to $a$ crown group $b$ (such as the mitrates); $c$ is a plesion (see ref. 1) defined by evolutionary novelties (heavy arrows) along the stem lineage (between $x$ and $y$ ). The stem group and plesion are clearly paraphyletic. The left-hand side of the diagram illustrates the original plesion concept ${ }^{17}$. The fossil taxon $e$ is incorporated in a character analysis built using data from living forms only to lie as a monophyletic sister group of $d$, which may contain extinct forms, living forms, or both; $e$ is referred to as a plesion, but note that it is a monophyletic group used to express character distributions only, and not a paraphyletic group such as $c$ which essentially summarizes a grade of organization.

\title{
Rock Festival at British Museum
}

THIs sample of aragonite from Cumberland features in a new exhibition at the Geological Museum in Cromwell Road, London SW7, now part of the British Museum (Natural History). The 'Rock Festival' features the world of minerals in nature and art and runs until 15 January 1990. Originally developed by the city of Strasbourg as part of its bimillenial celebrations, the exhibition also highlights many of the museum's own specimens.

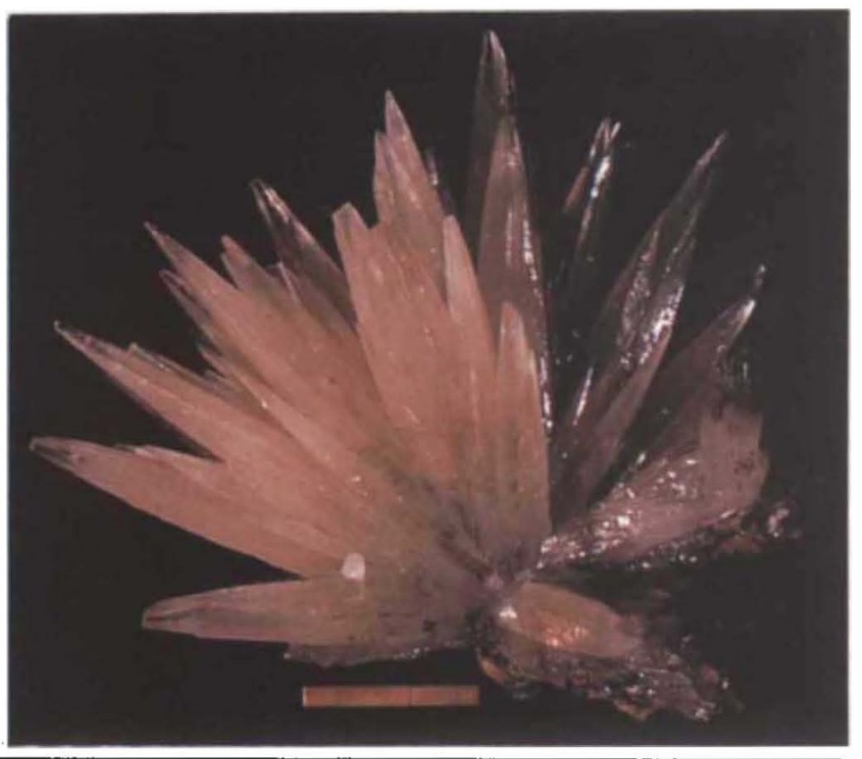

group of carpoids, called mitrates, as crown-group chordates which retain calcite skeletons. He suggests that there are three separate stem groups within the mitrates, leading, respectively, to acraniates (such as the amphioxus Branchiostoma), the tunicates and the vertebrates. Every known mitrate can be assigned to one of these stem groups ${ }^{3}$. Barrandeocarpus is the member of a plesion in the vertebrate stem group within mitrates, but is somewhat removed from the actual vertebrate stem lineage. Defining its precise position has led to a new method of subdividing plesions ${ }^{1}$

Jefferies' theory is by no means generally accepted ${ }^{9}$, and the loss of the calcite skeleton is a particular stumbling block. Jefferies claims that calcite resorption can be seen in some mitrates such as Mitrocystella, but even if calcite had been lost in this way, many questions about the nature of the calcichordate integument remain unanswered. The only living animals with a calcichordate-type skeleton are echinoderms, and their integuments are fundamentally different in structure and function from those of chordates. Furthermore, the calcichordate fossil record seems to be at variance with the phylogeny reconstructed by Jefferies ${ }^{3}$. Calcichordates are known from Lower Palaeozoic rocks throughout the world, but almost all known examples postdate the earliest records of true, fish-like vertebrates. So if the calcichordate theory is correct, many examples remain to be discovered in Cambrian and Precambrian rocks. (Indeed, new species of calcichordate are still being found in Wales in the United Kingdom, where Lower Palaeozoic rocks are well-charted ${ }^{18}$.) Problems of completeness in the fossil record are best solved by digging rather than theorizing - but making the calcichordate theory fit the harsh realities of the fossil record may turn out to be its biggest difficulty.

In the meantime, the fossil species Jefferies uses to build his theory ${ }^{3}$ can be considered as abstract and timeless types rather than as real species, between which there are not evolutionary relationships but only affinities. Pre-evolutionary biologists (such as Linnaeus) classified organisms fairly well without invoking evolutionary change. Cladists accept that evolution happened, but prefer to ignore it as an explanatory process until its pattern has been worked out.

Nevertheless, others (including some of Jefferies' critics) think that the calcichordate theory - as a theory - is the best so far to explain chordate and vertebrate origins, in that it is the most self-consistent. For all its problems, and whether one believes it or not, the organization of an otherwise bewildering array of meticulously well-defined characters according to cladistic principles makes the calcichordate theory a hard act to follow.

Henry Gee is on the editorial staff of Nature

1. Craske, A.J. \& Jefferies, R.P.S. Palaeontology 32, 69-99 (1989)

2. Gislén, T. Zool. Bidr. Upps. 12, 199-304 (1930)

3. Jefferies, R.P.S. The Ancestry of the Vertebrates (British Museum (Natural History), London, 1986).

4. Jefferies, R.P.S. Bull. Br. Mus. nat. Hist. Geol. 16, 243 339 (1968)

Baker. R A \& Bayliss, R A. Naturalist 109, 41 (1984).

6. Garstang, W.Q. J. microsc. Sci. 72, 51-187 (1928)

7. Garstang, W. Zool. Anz. 17, 122-125 (1894)

8. Garstang, W. Zool. J. Linn. Soc. 35, 81-101 (1922)

9. Thomson, K.S. Nature 327, 196-197 (1987)

10. Hennig, W. Phylogenetic Systematics (University of Illinois Press, Urbana, 1966)

11. Forey, P.L. in Problems of Phylogenetic Reconstruction (eds Joysey, K.A. \& Friday, A.E.) 119-157 (Academic. London, 1982)

12. Løvtrup, S. Syst. Zool. 34, 463-470 (1985)

13. Gardiner, B.G. Zool. J. Linn. Soc. 74, 207-232 (1982)

14. Gee, H. Nature 334, 13-14 (1988).

15. Gauthier, J. Kluge, A.G. \& Rowe, T. Cladistics 4, 104 209 (1988).

16. Ax, P. Das Phylogenetische System (Fischer, 1984)

17. Patterson, C. \& Rosen, D.E. Bull. Am. Mus nat. Hist. 158, 85-172 (1977)

18. Jefferies, R.P.S. Geol. Today 211-213 (Nov-Dec 1988). 